\title{
What is the impact of serum and follicular fluid BMP-15 and AMH levels in ICSI-ET cycle outcomes?
}

\author{
Rasit Ilhan ${ }^{1}$, Zehra Sema Ozkan ${ }^{1,3 *}$, Mustafa Ekinci', Huseyin Timurkan ${ }^{1}$ and Necip İlhan ${ }^{2}$ \\ ${ }^{1}$ Firat University Hospital, Department of Obstetrics and Gynecology, IVF Unit, Elazig, Turkey \\ ${ }^{2}$ Firat University School of Medicine, Department of Biochemistry, Elazig, Turkey \\ ${ }^{3}$ Kirikkale University Hospital, Department of Obstetrics and Gynecology, Kirikkale, Turkey
}

\begin{abstract}
Objective: Bone morphogenetic protein-15 (BMP-15) and anti-Müllerian hormone (AMH) are the proteins functioning during ovarian follicular growth. We aimed to investigate the impact of serum and follicular fluid (FF) AMH and BMP-15 levels on outcomes of intracytoplasmic sperm injection- embryo transfer (ICSI-ET) cycles.

Methods: This prospective, cross-sectional study was carried out with 82 patients attending ICSI-ET cycle. The women divided into two groups according to using either $\mathrm{GnRH}$ agonist (group1, N=38) or antagonist (group2, $\mathrm{N}=44$ ) for pituitary down-regulation. Eight milliliter of serum samples were taken from the patients on the 3rd day of menstrual period (D3) and on the day of oocyte pick-up (OPU); and $8 \mathrm{~mL}$ of follicular fluid (FF) sample was collected during OPU. AMH and BMP-15 measurements were carried with ELISA method quantitatively.

Results: The mean age and body mass index of population were $30.6 \pm 5.2$ years and $25.5 \pm 4.2 \mathrm{~kg} / \mathrm{m}^{2}$ respectively. The comparison of pregnancy rates between women according to having FF AMH (35\% vs 42\%) and FF BMP-15 (37.8\% vs 40.5\%) levels under and above of the mean values revealed no significant difference. Serum AMH levels showed negative correlation with fertilization rate (FR). D3 BMP-15 level showed positive correlation with progesterone level and endometrial thickness on the day of hCG injection.
\end{abstract}

Conclusions: AMH and BMP-15 monitoring during ICSI-ET cycles for predicting cycle outcomes should be evaluated with further studies.

\section{Introduction}

Bone morphogenetic protein-15 (BMP-15) and anti-Müllerian hormone (AMH) are the members of transforming growth factorbeta superfamily. BMP-15 and its receptor are widely expressed in the mammalian female reproductive system especially in oocytes [1]. BMP-15 plays role on mammalian oocyte maturation by cumulus oophorus complex expansion [2,3]. AMH is produced by the ovarian granulosa cells and supports the follicular growth [4]. Effect of AMH and BMP-15 on estradiol and progesteron production in primarycultured human luteinizing granulosa cells was reported [5]. BMP-15 level in follicular fluid has been demonstrated to associate with oocyte and embryo quality [6]. Researchers observed relation among cumulus cell BMP15 expression level and oocyte maturation, fertilization, and embryonic development [7]. And also follicular fluid AMH levels showed correlation with ovarian stimulation parameters and qualities of oocyte and embryo [8,9]. Researchers suggested that AMH could be a marker in the pre-treatment period for live birth chance in women with decreased ovarian reserve [4]. In this study we aimed to investigate 1-) the possible relation between follicular fluid and serum $\mathrm{AMH}$ and BMP-15 levels and intracytoplasmic sperm injection-embryo transfer (ICSI-ET) cycle outcomes, and 2-) the possible difference for fluid and serum AMH and BMP-15 levels according to using either gonadotropin-releasing hormone $(\mathrm{GnRH})$ agonist or antagonist.

\section{Materials and methods}

This prospective, cross-sectional study was conducted with 82 women attending controlled ovarian hyperstimulation (COH)ICSI-ET cycle in In Vitro Fertilization (IVF) Unit of Firat University Hospital between June 2012 and June 2013 after approval of local ethical committee. The women divided into two groups according to using either GnRH agonist (group1, N=38) or antagonist (group2, $\mathrm{N}=44$ ) for pituitary down-regulation. The exclusion criterias were as follows: age $>39$ years, gynaecological malignancy diagnosis during evaluation, absence of sperm after testicular sperm extraction.

\section{Controlled Ovarian Hyperstimulation and Embryo Transfer}

Gynecological examination, antral follicle count, FSH-LHestradiol-TSH-prolactin level evaluation on day 3 (D3) of menstrual period, hysterosalpingography/hysteroscopy and semen analysis were performed.

In group1; GnRH agonist leuprolide acetate (Lucrin daily ${ }^{\circledR}$, Abbvie, Istanbul, Turkey) was started on day 21 of previous cycle and proceeded to the day of human chorionic gonadotropin (hCG) injection according to long luteal protocol $(0.1 \mathrm{mg} /$ day, subcutaneous from day 21 and reduction to $0.05 \mathrm{mg}$ /day on stimulation). In group2;

Correspondence to: Zehra Sema Özkan, Kirikkale University Hospital, Department of Obstetrics and Gynecology, Kırıkkale, 71451, Turkey, Tel: +905053983219; E-mail: zehrasema@yahoo.com

Key words: AMH, BMP-15, fertilization rate, follicular fluid, ICSI-ET cycle

Received: May 10, 2017; Accepted: June 20, 2017; Published: June 23, 2017 
GnRH-antagonist ganirelix acetate (Orgalutran ${ }^{\circledR}$, Organon, Istanbul, Turkey) or cetrorelix acetate (Cetrotide, Merck Serono, Istanbul, Turkey) was initiated $0,25 \mathrm{mg}$ daily when one of the following criteria was met: presence of at least one leading follicle $>12 \mathrm{~mm}$, or estradiol level exceeding $300 \mathrm{pg} / \mathrm{mL}$. GnRH antagonist was continued to the day of hCG injection. Gonadotropin stimulation was started as 150-225 IU for normoresponders and 375-450 IU for poor responders according to each patient's basal antral follicle count, day-3 hormonal status, body mass index (BMI), and prior response. Either recombinant FSH (Puregon;, Organon, Istanbul, Turkey or Gonal-F;, Merck Serono, Istanbul, Turkey), or human menopausal gonadotropin (hMG, Merional', IBSA Pharmaceuticals, Istanbul, Turkey), or usually a combination of two were used together.

Ovarian response was monitored by transvaginal ultrasound and serum levels of estradiol measurements. When at least three follicles with a mean diameter exceeding $17 \mathrm{~mm}$ were measured, 250 mcg recombinant hCG (Ovitrelle', Merck Serono, Istanbul, Turkey) was administered. Oocytes were picked up (OPU) by transvaginal ultrasound-guided follicular puncture 35 to 36 hours after hCG administration. Embryo transfer (ET) was performed on day 3 or 5 by using a soft catheter (Wallace, Smiths Medical, Kent, UK) under guidance of transabdominal ultrasound. Luteal phase supplementation was done with vaginal progesterone gel twice a day (Crinone $8 \%$ gel, 90 mg; Merck Serono, Istanbul, Turkey) starting on the oocyte retrieval day. Beta-hCG levels were measured 12 days after ET. Fertilization rate (FR) is calculated as the ratio of two ponucleus/mature oocyte number. Grade1 embryo quality was accepted as symmetrical blastomeres and no fragmentation. Implantation rate (IR) is calculated as gestational sac number/transferred embryo number. Clinical pregnancy is accepted as intrauterine fetal cardiac activity positivity.

\section{ELISA}

Peripheric eight milliliter venous blood samples for analysis of $\mathrm{AMH}$ and BMP-15 levels were taken on day 3 of menstrual period (D3) and on the day of OPU. Follicular fluid (FF) samples were taken during OPU for analysis of AMH and BMP-15 levels, too. Serum and $\mathrm{FF}$ samples were stored at $-80^{\circ} \mathrm{C}$ until run time. Enzyme-linked immunosorbent assay (Diagnostic Systems Laboratories, Webster, Texas, USA) for AMH (Cusabio, catalog no $=$ CSB-E12756h, China) and BMP-15 (East Biopharma, catalog no= CK-E90147, USA) were performed according to manufacturer's instructions. Intra and inter assay variations were $<10 \%$ and $<12 \%$ respectively.

\section{Statistical analysis}

The statistical analyses were performed using Statistical Package for Social Sciences version 16.0 (SPSS Inc., USA). Distribution of the continuous variables was checked by using the Kolmogorov-Smirnov One Tailed test. Student's $t$-test was used for variables with normal distribution. After testing the skewed distribution, comparisons between the groups were tested by using the Mann-Whitney $U$ test. The repetitive comparisons in the same group were done with Wilcoxon signed Rank Test. To prevent the inflation of significancy, Bonferroni correction was performed ( $\mathrm{P}$ value/ the number of comparisons being made; $\mathrm{P}<0.017$ was considered as statistically significant). The $\mathrm{X}^{2}$ test and Fisher's exact test were used to analyze nominal variables. Spearman correlation analysis and logistic regression analysis were applied to investigate the possible relation between AMH and BMP15 levels and ICSI-ET cycle outcomes. $\mathrm{P}<0.05$ was considered as statistically significant for whole comparisons.

\section{Results}

The mean age and body mass index of study population were $30.6 \pm 5.2$ years and $25.5 \pm 4.2 \mathrm{~kg} / \mathrm{m}^{2}$ respectively. Clinical characteristics of all women in the study were presented in Table 1. Comparison of clinical parameters between groups revealed no significant difference.

The stimulation and embryology parameters of two groups were presented in Table 2. Total oocyte number and estradiol level on the day of hCG injection were significantly higher in groupl compared to those in group2. There was no significant difference between groups for the parameters of mature oocyte number, gradel embryo number on the day of ET, rates of fertilization, implantation, pregnancy and clinical pregnancy.

There was no significant difference between groups for the parameters of D3, OPU and FF AMH and BMP-15 levels (Table 3). The comparison of pregnancy rates between women according to having FF AMH (35\% vs. 42\%) and BMP-15 (37.8\% vs. 40.5\%) levels under and above of mean values revealed no significant difference. And also,

Table 1. Clinical characteristics of all women in the study.

\begin{tabular}{|l|c|}
\hline \multicolumn{1}{|c|}{ Characteristics } & Mean \pm SD $/ \%$ \\
\hline Age (years) & $30.6 \pm 5.2$ \\
\hline Infertility type & \\
\hline -Primary & 69.5 \\
\hline -Secondary & 30.5 \\
\hline Infertility duration (months) & $60.1 \pm 43$ \\
\hline Infertility etiology & 35.4 \\
\hline -Unexplained & 22 \\
\hline -Anovulation & 25.6 \\
\hline -Male factor & 9.8 \\
\hline -Decreased ovarian reserve & 7.3 \\
\hline -Tubal factor & $25.5 \pm 4.2$ \\
\hline BMI (kg/m ${ }^{2}$ ) & $6.3 \pm 1.9$ \\
\hline D3 FSH (mIU/mL) & $5.4 \pm 3.3$ \\
\hline D3 LH (mIU/mL) & $45.2 \pm 23.5$ \\
\hline D3 Estradiol (pg/mL) & $2 \pm 1.9$ \\
\hline TSH (mIU/L) & $12.6 \pm 3.7$ \\
\hline Antral follicle count & \\
\hline
\end{tabular}

Note: $\mathrm{BMI}=$ body mass index; D3=day 3 of menstrual period; $\mathrm{FSH}=$ follicle stimulating hormone; $\mathrm{LH}=$ luteinizing hormone; $\mathrm{TSH}=$ thyroid stimulating hormone

Table 2. Stimulation and Embryology Characteristics of Groups

\begin{tabular}{|l|c|c|c|}
\hline Parameters & Group 1 & Group 2 & P value \\
\hline Total recombinant FSH dose (IU) & $\mathbf{( N = 3 8 )}$ & $\mathbf{( N = 4 4 )}$ & \\
\hline Total hMG dose (IU) & $459.9 \pm 124.5$ & $948.9 \pm 206.9$ & NS \\
\hline Stimulation duration (days) & $9.6 \pm 0.2$ & $9.8 \pm 1.7$ & NS \\
\hline Total oocyte number & $14.5 \pm 0.9$ & $11.2 \pm 0.9$ & $<\mathbf{0 . 0 1}$ \\
\hline Mature oocyte number & $9.42 \pm 0.9$ & $9.02 \pm 0.8$ & NS \\
\hline Two pronucleus number & $6.74 \pm 0.7$ & $6.5 \pm 0.6$ & NS \\
\hline Fertilization rate(\%) & 70 & 74 & NS \\
\hline Grade1 embryo number on the day of ET & $2.13 \pm 0.3$ & $1.93 \pm 0.2$ & NS \\
\hline Estradiol level on the day of hCG (pg/mL) & $3054.2 \pm 203$ & $2161.2 \pm 143.9$ & $<\mathbf{0 . 0 1}$ \\
\hline $\begin{array}{l}\text { Endometrial thickness on the day of hCG } \\
\text { (mm) }\end{array}$ & $13.78 \pm 3.6$ & $10.5 \pm 0.4$ & NS \\
\hline Progesteron level on the day oghCG (ng/mL) & $0.95 \pm 0.1$ & $0.97 \pm 0.1$ & NS \\
\hline Pregnancy rate/ per cycle (\%) & 29 & 48 & NS \\
\hline Pregnancy rate/ per ET (\%) & 33 & 51 & NS \\
\hline Implantation rate (\%) & 18 & 23 & NS \\
\hline Clinical pregnancy rate (\%) & 24 & 32 & NS \\
\hline
\end{tabular}

Note: $\mathrm{FSH}=$ follicle stimulating hormone; $\mathrm{hMG}=$ human menopausal gonadotrophin; 
according to this classification; there was no significant difference between groups for parameters of FR and IR, too.

The comparison of AMH and BMP-15 levels between women became pregnant or not revealed no significant difference, too.

The results of correlation analysis between parameters for whole population were presented in Table 4. In both of groups, FF AMH and BMP-15 levels were significantly higher than D3 and OPU AMH and BMP-15 levels $(\mathrm{p}<0.05)$. D3 AMH level showed positive correlation with OPU and FF AMH levels $(\mathrm{p}<0.05)$. D3 and OPU AMH levels showed negative correlation with fertilization rate $(\mathrm{FR})(\mathrm{p}<0.01)$. In regression analysis; $\mathrm{D} 3 \mathrm{AMH}$ level $(\mathrm{OR}=0.5,95 \% \mathrm{CI}=0.010-0.091$, $\mathrm{p}<0.05)$ and OPU AMH level $(\mathrm{OR}=0.9,95 \% \mathrm{CI}=0.025-0.070, \mathrm{p}<0.05)$ showed minimal influence on FR.

OPU BMP-15 level showed negative correlation with FF BMP15 level $(\mathrm{p}<0.05)$. D3 BMP-15 level showed positive correlation with progesterone level and endometrial thickness on the day of hCG injection $(\mathrm{p}<0.05)$. In regression analysis; D3 BMP-15 level showed minimal influence on progesterone level $(\mathrm{OR}=0.9,95 \% \mathrm{CI}=0.020$ $0.025, \mathrm{p}<0.01)$ and endometrial thickness $(\mathrm{OR}=0.6,95 \% \mathrm{CI}=0.238$ $0.383, \mathrm{p}<0.01)$ on the day of hCG injection.

\section{Discussion}

Our main findings with this study were as follows: 1-) We did not observe difference between GnRH agonist or antagonist users for serum and FF AMH and BMP-15 levels. 2-) Both of serum AMH levels (D3 and OPU) showed negative correlation with FR. 3-) D3 BMP-15 level showed positive correlation with progesterone level and endometrial thickness on the day of hCG injection. 4-) OPU BMP-15 levels showed negative correlation with FF BMP-15 levels.

Researchers observed the enhancing effect of culture medium enriched with BMP-15 on embryo quality in animal studies [10].

Table 3. Comparison of AMH ve BMP-15 levels between Group 1 and 2.

\begin{tabular}{|l|c|c|c|}
\hline Parameters & Group1 & Group2 & P value \\
\hline D3 AMH $(\mathrm{ng} / \mathrm{mL})$ & $\mathbf{( N = 3 8 )}$ & $\mathbf{( N = 4 4 )}$ & \\
\hline OPU AMH $(\mathrm{ng} / \mathrm{mL})$ & $3.4 \pm 0.9$ & $4.4 \pm 1.6$ & 0.19 \\
\hline FF AMH $(\mathrm{ng} / \mathrm{mL})$ & $8 \pm 1.4$ & $10.3 \pm 2.6$ & 0.26 \\
\hline D3 BMP 15 $(\mathrm{ng} / \mathrm{mL})$ & $558 \pm 28$ & $570 \pm 28$ & 0.05 \\
\hline OPU BMP 15 $(\mathrm{ng} / \mathrm{mL})$ & $41.8 \pm 2.3$ & $39.2 \pm 1.3$ & 0.45 \\
\hline FF BMP $15(\mathrm{ng} / \mathrm{mL})$ & $38.2 \pm 2.2$ & $36.6 \pm 1.8$ & 0.8 \\
\hline
\end{tabular}

Note: Values are presented as Mean $\pm \mathrm{SEM} . \mathrm{AMH}=$ anti mullerian hormone;

BMP-15= bone morphogenetic protein 15; D3= day 3 of menstrual period;

$\mathrm{OPU}=$ oocyte pick-up; $\mathrm{FF}=$ follicular fluid

Table 4. Correlation analysis of AMH and BMP-15 levels with clinical parameters.

\begin{tabular}{|c|c|c|c|}
\hline Parameter & Parameter & R & P value \\
\hline \multirow{2}{*}{ D3-AMH } & OPU-AMH & 0.32 & $<0.01$ \\
\cline { 2 - 4 } & FF-AMH & 0.25 & 0.02 \\
\cline { 2 - 4 } & Fertilization rate & -0.38 & $<0.01$ \\
\hline \multirow{2}{*}{ OPU-AMH } & FF-AMH & 0.28 & $<0.01$ \\
\cline { 2 - 4 } & Fertilization rate & -0.38 & $<0.01$ \\
\hline FF-AMH & Age & 0.28 & 0.01 \\
\hline D3-BMP15 & hCGprogesteron & 0.22 & 0.04 \\
\hline \multirow{2}{*}{ OPU-BMP15 } & hCGendometrium & 0.39 & $<0.01$ \\
\hline
\end{tabular}

Note: $\mathrm{D} 3=$ day 3 of menstrual period; $\mathrm{AMH}=$ anti mullerian hormone; $\mathrm{FF}=$ follicular fluid BMP-15= bone morphogenetic protein -15 ; $\mathrm{hCG}=$ human chorionic gonadotropin; $\mathrm{OPU}=$ oocyte pick-up
Requena et al.studied FF BMP-15 levels of 90 women attended controlled ovarian stimulation for donation. They compared FF BMP15 level among recombinant FSH, urinary FSH and hMG groups with Western blot analysis and they did not observe significant difference among groups [11]. Wu et al.,investigated the effect of FF BMP-15 on implantation among 207 poor responder women experiencing $\mathrm{COH}$ ICSI-ET cycle. They classified their population according to having FF BMP-15 level lower than mean value and higher than mean value. They observed significantly higher IR in 97 women with high FF BMP15 level than 110 women with low FF BMP-15 level [12]. But in our population we did not observe significant differences for IR, FR and pregnancy rate between women either having lower or higher FF BMP15 levels than mean value. And also in our population FF BMP-15 level showed negative correlation with OPU-BMP-15 level. Genereally it was expected that increased FF BMP-15 level should increase the OPU BMP-15 level, too. But in our study we did not observe increased serum BMP-15 level on the day of OPU. This condition may be the result of production of BMP-15 from a different tissue or elimination during transition from FF to blood. Gode et al.,studied FF BMP-15 expression levels in 81 infertile women experiencing COH-ICSI-ET cycle. They did not observe significant difference in embryo quality among women regarding to BMP-15 expression status [13]. Wu et al., reported significantly increased FF BMP-15 levels in poor responders compared to that in normoresponders [14]. Researchers evaluated FF BMP-15 levels of 79 couples enrolled long luteal COH-ICSI programme due to male factor infertility. They compared FF BMP-15 levels of fertilized 60 oocytes with unfertilized 19 oocytes. FF BMP-15 level of fertilized oocytes were significantly higher than that of unfertilized oocytes [6]. Gueripel et al.,observed increased BMP-15 immunostaining on ovarian tissue of mouse stimulated with gonadotropins [15]. In our population; D3 BMP-15 level showed positive correlation with progesterone level on the day of hCG injection. Increased D3 BMP-15 level may be considered as a negative predictor for follicular development during $\mathrm{COH}$.

The studies performed for investigating the role of FF AMH levels on ICSI-ET cycle outcome revealed different results. Some researchers observed no relation between $\mathrm{COH}$ outcome parameters and FF AMH level [16,17]; others observed positive correlation with FF AMH level and embryo quality [9]. The studies about dynamic change of serum AMH during $\mathrm{COH}$ with $\mathrm{GnRH}$ antagonist reported gradual decreament from stimulation start to hCG injection [18,19]. But in our study we observed gradual increament for serum AMH levels from start of stimulation to day of OPU in cycles down regulated with either GnRH agonist or antagonist. Researchers appointed significantly lower FF AMH levels in fertilized oocytes compared to that in non-fertilized oocytes [20]. Mehta et al.,compared FR and IR according to FF AMH level either higher or lower than median value in 132 conventional IVF-ET cycle. They observed significantly higher FR and IR in women with low FF AMH levels compared to those with high FF AMH levels [21]. Researchers observed significantly high FF AMH levels in women became pregnant after long luteal-phase down regulated ICSI-ET cycle. Chen et al., analysed FF AMH levels of 64 women enrolled long lutealphase down regulated ICSI-ET cycle. They observed higher FF AMH levels in pregnant women compared to that in non-pregnant women. And also they observed correlation between FF AMH level and IR [22]. Hattori et al.,investigated FF AMH levels in 58 women attending ICSIET cycle with mixed infertility etiology. They reported significantly high FF AMH levels in women became pregnant compared to that in non-pregnant [23]. Wunder et al.,observed significantly higher serum and FF AMH levels in women conceived after IVF/ICSI treatment 
compared to those in women not conceived [24]. In our study we did not observe significant difference for FF AMH levels between women became pregnant or not. Ashrafi et al., pointed out that serum AMH is not a good predictor for clinical pregnancy and live birth rates in IVF/ICSI cycles [25]. Takahashi et al., observed no relation between serum AMH level and ratio of high grade embryo quality [26]. And also Mashiach et al., observed no significant relation between FF AMH level and FR and cleavage rate among $22 \mathrm{FF}$ sample of 11 polycystic ovary syndrome patients undergoing IVF [27]. However other researchers notified relation between serum AMH level and IR in 42 normoresponder women experiencing IVF [28]. Lee et al., observed no significant difference for FF AMH levels between $43 \mathrm{GnRH}$ agonist vs $44 \mathrm{GnRH}$ antagonist users [29]. But in our study; FF AMH level of $\mathrm{GnRH}$ agonist users was significantly lower than that of $\mathrm{GnRH}$ antagonist users. And also in our population; FF AMH level showed influence on FR and IR. The different results among the studies may arise from population heterogeneities.

The limitations in our study were as follows: 1-) The study population was consisted of heterogenous infertility etiology. To exclude the confounding factors on oocyte and sperm quality, the population should be composed of only tubal factor infertility. 2-) BMP-15 and AMH expression levels of COC will give more detailed information about microenviroment of oocyte than FF.

In conclusion; FF AMH level may show a prognostic value for prediction of FR and IR in ICSI cycles. The negative correlation between OPU BMP-15 and FF BMP-15 levels must be evaluated with further expanded population studies.

\section{Acknowledgement}

This study was supported by Firat University Scientific Research Foundation (FÜBAP).

\section{Declaration of interest statement} disclose.

All of the authors declare that they have no conflict of interest to

\section{References}

1. Erickson GF, Shimasaki S (2003) The spatiotemporal expression pattern of the bone morphogenetic protein family in rat ovary cell types during the estrous cycle. Reprod Biol Endocrinol 1: 9.[Crossref]

2. Caixeta ES, Sutton-McDowall ML, Gilchrist RB, Thompson JG, Price CA, et al. (2013) Bone morphogenetic protein 15 and fibroblast growth factor 10 enhance cumulus expansion, glucose uptake, and expression of genes in the ovulatory cascade during in vitro maturation of bovine cumulus-oocyte complexes. Reproduction 146:27-35. [Crossref]

3. Peng J, Li Q, Wigglesworth K, Rangarajan A, Kattamuri C, et al. (2013) Growth differentiation factor 9: bone morphogenetic protein 15 heterodimers are potent regulators of ovarian functions. Proc Natl Acad Sci USA 110: E776-785. [Crossref]

4. Reijnders IF, Nelen WL, IntHout J, van Herwaarden AE, Braat DD et al. (2016) The value of Anti-Müllerian hormone in low and extremely low ovarian reserve in relation to live birth after in vitro fertilization. Eur J Obstet Gynecol Reprod Biol 200: 45-50. [Crossref]

5. Prapa E, Vasilaki A, Dafopoulos K, Katsiani E, Georgoulias P, et al. (2015) Effect of Anti-Müllerian hormone (AMH) and bone morphogenetic protein 15 (BMP-15) on steroidogenesis in primary-cultured human luteinizing granulosa cells through Smad5 signalling. J Assist Reprod Genet 32: 1079-1088. [Crossref]

6. Wu YT, Tang L, Cai J, Lu XE, Xu J, et al. (2007) High bone morphogenetic protein-15 level in follicular fluid is associated with high quality oocyte and subsequent embryonic development. Hum Reprod 22: 1526-1531. [Crossref]

7. Li Y, Li RQ, Ou SB, Zhang NF, Ren L, et al. (2014) Increased GDF9 and BMP15 mRNA levels in cumulus granulosa cells correlate with oocyte maturation, fertilization, and embryo quality in humans. Reprod Biol Endocrinol 12: 81. [Crossref]

8. Salmassi A, Mettler L, Hedderich J, Jonat W, Deenadayal A, et al. (2015) Cut-Off Levels of Anti-Mullerian Hormone for The Prediction of Ovarian Response, In Vitro Fertilization Outcome and Ovarian Hyperstimulation Syndrome. Int J Fertil Steril 9: 157-167. [Crossref]

9. Kim JH, Lee JR, Chang HJ, Jee BC, Suh CS, et al. (2014) Anti-Müllerian hormone levels in the follicular fluid of the preovulatory follicle: a predictor for oocyte fertilization and quality of embryo. J Korean Med Sci 29: 1266-1270.[Crossref]

10. Machado MF, Caixeta ES, Sudiman J, Gilchrist RB, Thompson JG, et al. (2015) Fibroblast growth factor 17 and bone morphogenetic protein 15 enhance cumulus expansion and improve quality of in vitro-produced embryos in cattle. Theriogenology 84: 390-398. [Crossref]

11. Requena A, Cruz M, Agudo D, Pacheco A, García-Velasco GA (2016) Type of gonadotropin during controlled ovarian stimulation affects the endocrine profile in follicular fluid and apoptosis rate in cumulus cells. Eur J Obstet Gynecol Reprod Biol 197:142-146.

12. Wu YT, Wang TT, Chen XJ, Zhu XM, Dong MY, et al. (2012) Bone morphogenetic protein-15 in follicle fluid combined with age may differentiate between successful and unsuccessful poor ovarian responders. Reprod Biol Endocrinol 10: 116. [Crossref]

13. Gode F, Gulekli B, Dogan E, Korhan P, Dogan S, et al. (2011) Influence of follicular fluid GDF9 and BMP15 on embryo quality. Fertil Steril 95: 2274-2278. [Crossref]

14. Wu YT, Lu XE, Wang TT, He RH, Xu J, et al. (2007) Women with poor response to ovarian stimulation have increased follicular bone morphogenetic protein-15 levels. Zhejiang Da Xue Xиe Bao Yi Xue Ban 36: 439-442.[Crossref]

15. Guéripel X, Brun V, Gougeon A (2006) Oocyte bone morphogenetic protein 15, but not growth differentiation factor 9 , is increased during gonadotropin-induced follicular development in the immature mouse and is associated with cumulus oophorus expansion. Biol Reprod 75: 836-843. [Crossref]

16. Melado Vidales L, Fernandez Nistal A, Martinez Fernandez V, et al. (2016) AMH levels to predict oocyte maturity and embryo quality during controlled ovarian hyperstimulation. Minerva Ginecol 69: 225-232.[Crossref]

17. Bastu E, Gokulu SG, Dural O, Yasa C3, Bulgurcuoglu S, et al. (2015) The association between follicular fluid levels of cathepsin B, relaxin or AMH with clinical pregnancy rates in infertile patients. Eur J Obstet Gynecol Reprod Biol 187: 30-34. [Crossref]

18. VidalesML, Fernandez-Nistal A, Fernandez VM, Merino VV, Catalan IB, et al. (2016) Anti-müllerian hormone dynamics during GNRH-antagonist short protocol for IVF/ ICSI in women with varying ovarian reserve levels. Minerva Ginecol Jun 16.[Crossref]

19. Li Y, Nie M, Liu Y, Zhang W, Yang X (2015) The dynamic changes of anti-Mullerian hormone and inhibin B during controlled ovarian hyperstimulation in decreased ovarian reserve women and the effect on clinical outcome. Gynecol Endocrinol 31: 450-453. [Crossref]

20. Milaković T, Horvat PL, Čavlović K, Severinski SN, Vlašić H, et al. (2015) Follicular fluid anti-Müllerian hormone: a predictive marker of fertilization capacity of MII oocytes. Arch Gynecol Obstet 291: 681-687.[Crossref]

21. Mehta BN, Chimote MN, ChimoteNM, Chimote NN, Nath N(2013) Follicular-fluid anti-Mullerian hormone (FF AMH) is a plausible biochemical indicator of functional viability of oocyte in conventional in vitro fertilization (IVF) cycles. J Hum Reprod Sci $6: 99-105$. [Crossref]

22. Chen X, Yin M, Ye D, He Y, Chen S (2013) Predictive value of anti-Mullerian hormone levels in serum and follicle fluid for IVF-ET outcomes in patients with polycystic ovarian syndrome. Nan Fang Yi KeDaXueXue Bao 33: 546-549.[Crossref]

23. Hattori Y, Sato T, Okada H, Saito C, Sugiura-Ogasawara M (2013) Comparison of follicular fluid and serum anti-Mullerian hormone levels as predictors of the outcome of assisted reproductive treatment. Eur J Obstet Gynecol Reprod Biol 169: 252-256. [Crossref]

24. Wunder DM, Guibourdenche J, Birkhäuser MH, Bersinger NA (2008) Anti-Müllerian hormone and inhibin B as predictors of pregnancy after treatment by in vitro fertilization/intracytoplasmic sperm injection. Fertil Steril 90: 2203-2210.[Crossref]

25. Ashrafi M, Hemat M, Arabipoor A, Salman YR, Bahman-Abadi A, et al. (2016) Predictive values of anti-müllerian hormone, antral follicle count and ovarian response prediction index (ORPI) for assisted reproductive technology outcomes. $J$ Obstet Gynaecol 1: 82-88. [Crossref]

26. Takahashi C, Fujito A, Kazuka M, Sugiyama R, Ito H, et al. (2008) Anti-Müllerian hormone substance from follicular fluid is positively associated with success in oocyte fertilization during in vitro fertilization. Fertil Steril 89: 586-591.[Crossref] 
27. Mashiach R, Amit A, Hasson J, Amzalzg S, Almog B, et al. (2010) Follicular fluid levels of anti-Mullerian hormone as a predictor of oocyte maturation, fertilization rate, and embryonic development in patients with polycystic ovary syndrome. Fertil Steril 93: 2299-2302. [Crossref]

28. Arabzadeh S, Hossein G, Rashidi BH, Hosseini MA, Zeraati H (2010) Comparing serum basal and follicular fluid levels of anti-Müllerian hormone as a predictor of in vitro fertilization outcomes in patients with and without polycystic ovary syndrome. Ann Saudi Med 30: 442-447.[Crossref]

29. Lee JR, Kim SH, Kim SM, Jee BC, Ku SY, et al. (2008) Follicular fluid anti-Müllerian hormone and inhibin $\mathrm{B}$ concentrations: comparison between gonadotropin-releasing hormone $(\mathrm{GnRH})$ agonist and GnRH antagonist cycles. Fertil Steril 89: 860-867. [Crossref]

Copyright: $(02017$ Ilhan R. This is an open-access article distributed under the terms of the Creative Commons Attribution License, which permits unrestricted use, distribution, and reproduction in any medium, provided the original author and source are credited. 